\title{
The touring reader: Understanding the bibliophile's experience of literary tourism
}

\section{Abstract}

This research explores the literary enthusiast's experience of planning and undertaking literary inspired trips. The research reconceptualises the dominant figure of the literary pilgrim, inspired to visit sites associated with favourite authors, by using detailed results from 30 open-ended surveys distributed to delegates at a literary conference. The findings indicate that these keen readers prefer to plan their own trips and shun organised attractions and mainstream tourist information in favour of employing the texts themselves as source material. Respondents then feed back their experiences into the re-reading of the literary text. These findings are analysed using the concept of concretisation borrowed from literary theory. This concept, which has not been used in previous tourist studies, reflects the experience of these visitors who are using travel to solidify their reading of favourite books. This research therefore highlights the interdependence of texts and travels and emphasises the important role that imagination plays in the experience and recollection of tourist trips. Keywords: Literary tourism; readers; pilgrims; tourist experience; concretisation; United Kingdom

\section{Introduction}

To travel under the influence of a favourite author, book or poem is an impulse dating back to the rise of the popular novel in the $18^{\text {th }}$ century. This activity continues to expand and many regions and sites exploit their literary connections, encouraging visitors to seek out places linked to authors' lives and their imaginative outpourings. We have also seen a similar interest in book towns, literary trails and festivals (MacLeod 2009; MacLeod, Hayes \& Slater, 2009; Robertson \& Yeoman, 2014; Saretzki, 2013). Visit England has declared 2017 to be Year of Literary Heroes (Figure 1), reporting that one in four Britons visited an English 
literary location in 2016 (VisitEngland, 2017). This flowering goes hand in hand with a strong demand for books and e-books, particularly in the top markets of USA, China and UK (IPA, 2016), and the continuing popularity of book groups and online literary discussion fora (Burger, 2015). This reflects the enduring appeal of the written word and underpins the ongoing desire to travel to expand this interest. Although this form of touring has a long history, academic research on literary tourism seems to have proliferated only since 1990 (Hoppen, Brown \& Fyall, 2014; O’Connor \& Kim, 2014) and has largely been concerned with case studies of specific literary tourism destinations (Busby, Brunt, \& Lund, 2003, Herbert 1996; Müller, 2006) and the tourism development potential of literary themes (Butler, 1986; Smith, 2012; Yiannakis \& Davies, 2012). Less emphasis seems to have been placed on the literary tourists themselves (Brown, 2015; Es \& Reijnders 2016) although several studies on defining the literary tourist as pilgrim have been undertaken (Brown, 2015; Busby \& Shetliffe, 2013; Herbert, 2001; Pocock, 1992). These studies tend to explore the literary pilgrim in situ and differentiate them from the more generalist visitor in terms of their knowledge of the author and their works and the purposefulness of their visit. They reveal a spectrum of literary interest ranging from those simply visiting a site whilst on a general tour to those who are devotees of a specific author or work and are purposefully seeking out associated settings.

\section{[Insert Figure 1 about here]}

This research seeks to contribute to these existing studies by focussing on the experiences, not of the pilgrim at the literary site, but of the reader as tourist. This study was prompted by the researchers' own (often shared) experiences of searching out specific sites associated with favourite texts and the realisation that much of the enjoyment is gained from self-discovery rather than visiting a demarcated site (Hoppen et al., 2014). Consequently, although the literary pilgrim seeking to commune with a favourite author at key biographical sites is a 
ubiquitous and long-standing figure in the field of literary tourism studies, the researchers were keen to discover if all enthusiastic readers could be thus defined or whether there are literary-inspired visitors who travel to enhance their experience of literature and do so without necessarily engaging with the sites and markers produced by the tourism industry. The aim of the research is therefore firstly, to research literary enthusiasts as tourists to ascertain their trip planning habits; secondly to evaluate the centrality of the literary text itself in relation to their travels; and thirdly, to determine what avid readers experience when on the literary trail. To this end, the literary pilgrim is reconceptualised within a co-construction paradigm, using a literary theory approach not found in tourist studies. In order to explore this theme, a cohort of self-confessed book lovers at a literary conference was used as the sample group for the research.

\section{Literature review}

This section reviews studies of the evolution of literary tourism with emphasis on the figure of the literary pilgrim. Various research approaches to the experience of the literary tourist are subsequently analysed.

\subsection{Evolution of literary tourism}

Literary tourism is defined as travel inspired by an association with authors or their literary works and studies in the field agree that these links can range from the autobiographical to the imaginative and often via the socially constructed as visitors seek out authorial birthplaces and burial sites alongside literary settings and purpose-built attractions conveying a literary theme (Fawcett \& Cormack, 2001; Herbert, 2001; Tetley \& Bramwell, 2002). Literary sites are therefore diverse with Gentile and Brown (2015) offering eight different typologies of literary-inspired sites including writers' homes, graves, bookshop tourism and literary festivals. UNESCO includes literature as part of its cultural landscape designation (Ruiz Scarfuto, 2013) and has now identified specific Cities of Literature with destinations 
such as Edinburgh and Melbourne recently winning this accolade (Hamilton \& Seale, 2014). The range of literary-themed destinations increases with the popularity of film and television adaptations of literary works encouraging more visitation, both actual and virtual (Gibson, 2006; Pennacchia, 2015; Troost, 2006). Literary tourism can in fact be considered as the forerunner of film and media-based tourism and in many cases the connections between these forms of tourism are very strong as O’Connor and Kim (2014) suggest. Mediatised literary locations reach out to wider film audiences and can also enrich the experiences of the literary tourist. Thus, contemporary Beatrix Potter fans can visit the Lake District in Cumbria, UK and see the farm where she lived and produced her children's books, experience the commercially-owned World of Beatrix Potter attraction and soak up the landscapes portrayed in the 2006 film biography, Miss Potter. Similarly, fans of novelist Charles Dickens can pay their respects at several former residences across London and Kent, absorb the atmosphere of a Dickensian London on a walking tour of the narrow alleyways of the City before (until recently) taking part in the theme-park experience of Dickens' World in Chatham, UK. Historically, tourism and literature have long enjoyed a close alignment and literary-inspired visits are associated with some of the earliest forms of travel and especially with the Grand Tour (Buzard, 1993; Hendrix, 2009; Ousby, 1990; Towner, 2002). A key event in the early years of organised literary tourism was David Garrick's Stratford Jubilee in 1769 (Santesso, 2004; Watson, 2006) although Santesso notes that traveller's interest in the birthplace of John Milton predates that famous celebration of William Shakespeare. Tourists were already stealing souvenir cuttings from Wordsworth's cottage garden in the Lakes by 1820 (Donaldson, Gregory \& Murrieta-Flores, 2015); a pocket travel version of Walter Scott's The Lady of the Lake had been produced for tourists' use by 1825 (Watson, 2006); and Burns Country had already been established in Ayrshire, Scotland by the early 19th century (MacKay \& Pittock, 2011), demonstrating that visiting a place with literary associates has 
long been a key motivation to travel within Britain. Further afield, Samuel Butler's utopian novel Erewhon was published in 1872 and within weeks, tourists were arriving at his Upper Rangita Valley home in New Zealand (Buchmann 2006); similarly, L.M Montgomery's Anne of Green Gables drew visitors to Canada's Prince Edward Island (the setting and authorial home) soon after its 1908 publication (Fawcett \& Cormack, 2001). Although historically a European or Anglophone activity (Yiannakis \& Davies, 2012), organised literary tourism is now found throughout the world - the first writer's home in China for example (Lu Xun, the nation's most celebrated modern writer), having been open in Shanghai since 1951 (Wang \& Zhang, 2017).

Literature also played a key role in prefiguring tourism in some locales, for example the Scottish Highlands as a romantic tourist destination was 'imagined into being' by literary and artistic representations rendering the area more attractive and accessible for early tourists in the $18^{\text {th }}$ century (Aitchison, MacLeod \& Shaw, 2002, p. 92). As an identifiable form of touring, literary-inspired travel has evolved in tandem with wider literary developments. Early tourists tended to be drawn to sites based on authorial biography but this was to change with the rapid growth of literary realism, where novels, plays and poems depicting actual sites were widely read and led to literary tourism's popularity in the 18th and 19th centuries. Watson (2006) traces this evolution of literary tourism from an intense interest in authors' birthplaces and other biographical sites towards a deeper engagement with the more imaginative aspects of the authorial output. This paradigm shift has been variously explained by the ascendance of romanticism and its deification of natural environments and extreme emotions (Lipovsek \& Kesic, 2015) and latterly to the concept of the death of the author (Philips, 2011; Wallace, 2009) where an interest in authorial biography was shunned in literary criticism circles and replaced by an elevation of the text as a free-standing, decontextualized entity, liberated from any authorial interpretation. However, it was 
conceptualised and enacted, literary tourism itself appears to be more popular with readers than writers with many authors remaining unconvinced of its value. Thus, we find Henry James satirising the consumption of authors' lives and locations and Thomas Hardy, John Ruskin, Virginia Woolf and Umberto Eco recording their views on the pointlessness of literary trips in comparison to the experience of the texts themselves (Booth, 2016; Donaldson et al., 2015; Eco, 1994); Smith, 2003). Their vested interest in the value of the written word (and perhaps their own privacy) may have shaped these opinions.

\subsection{Constructing the literary tourism experience}

Despite the contemporary prevalence of literary sites and manufactured experiences representing the 'commodification of the imagined and the imaginers' (Robinson 2002, p.7), literary-inspired tourism is not always a 'top-down imposition' (Robinson 2002, p. 13) from tourism providers but can evolve as an organic performance with active participation of the visitors themselves (O’Neill, Butts \& Busby, 2005; Jiang \& Xu, 2016). Such tourists actively read the landscape and look for clues, keen to layer their own meaning onto the site and use the texts to confirm their sense of place (Hoppen et al., 2014). There is considerable skill involved in this detection - Westover, for example, describes literary London as 'a palimpsest for the able decoder' (Westover, 2012, p. 6). There are real streets which are available to all visitors but these are layered over with 'disguised places' (Robinson 2002, p. 52) or imagined settings which only the tourist, informed by a more fictional guide, can access. The literary fan who is sufficiently motivated to seek out these imaginaries where no concrete sites exist, shows some resilience in their attempts as Light (2017) demonstrates in his analysis of Dracula fans in Transylvania, doggedly seeking out and appropriating likely locations for the Count despite the complete absence of vampires in the region's official tourism message. Literary fans confer with like-minded travellers and work together to track down likely locations, demonstrating "tourist to tourist knowledge exchange of 
interpretations, expectations and experiences of place" rendered more accessible through the increased use of social media (Lester \& Scarles 2016, p. 2). There are countless authors' homes, graves, trails, visitor centres, festivals and museums provided for the literary enthusiast to enjoy but some find just as much satisfaction from seeking out likely locations and inscribing their own narratives on the landscape without the intervention of any external agency.

\subsection{The literary tourist - beyond the pilgrim?}

This research explores the experience of readers as literary visitors and seeks to contribute to a literature where few studies of the motivations and experiences of literary tourists exist (Brown, 2015; Es \& Reijnders, 2016). As with research on special interest tourism more generally, which demarcates visitors depending on the strength of their purpose and engagement with their chosen activity (Novelli, 2005), attempts at segmenting the literary tourist tend to differentiate between the general heritage or leisure visitor and those with a much higher level of dedication to the literary theme portrayed (Busby \& Shetliffe, 2013). Watson suggests that in recent years literary touring has become a "widespread middle-class pursuit" (Watson, 2009, p. 38). However, despite the potentially wide range of visitors, the dominant trope in the study of the literary tourist is the figure of the literary pilgrim who has long provided a popular conceptual framework for thinking about this form of touring (Butler, 1986; Ousby, 1990). As part of the 'common language' of literary tourism, used prolifically in older accounts of such tours, the literary pilgrimage can be seen to replace the religious pilgrimage in a more secular world but still reflecting a mixture of 'high-minded sanctity and debased commercialism' characteristic of early Catholicism (Ousby, 1990, p. 22). The pilgrim is still a familiar figure in literary tourism studies such as Keith's review of the activities of Thomas Hardy devotees (1969), Pocock's analysis of pilgrims to Catherine Cookson Country (1992), Herbert's analysis of devoted fans at the homes of Proust, Dylan 
Thomas and Jane Austen (1996, 2001), Brooker's account of Lewis Carroll pilgrims (2005), Wallace's exploration of W.B. Yeats enthusiasts and Brown's personal accounts of her own pilgrimage to the graves of de Beauvoir and Sartre $(2015,2016)$. These studies, especially Pocock (1992), Herbert (2001) and Busby and Shetliffe (2013), conclude that this type of visitor is small in number, highly educated, from the service or managerial socio-economic groups and motivated by a desire to see real places associated with their favourite author. This is a purposeful and well-prepared traveller, described by Brown (2015) as "a dedicated scholar prepared to travel to experience places linked with favourite writers; the pilgrim is well educated and has the cultural capital to enjoy literary places" (p. 167). In particular, this type of visitor is keen to get as close as possible to the author themselves which Watson (2006), Brown (2015) and Robinson (2002) suggest explains the popularity of visiting writers' burial sites amongst this group of tourists. In tandem with achieving a sense of physical closeness and emotional association, the pilgrims are also keen to add to their existing knowledge of authors and their works and pay their respects (Brown, 2015). Literary pilgrims exhibit a detailed interest in all aspects of writers' lives and outputs, visiting shrines, homes and museums as well as experiencing the more imaginative locations evoked by the authors' work. Thus they will visit settings which are significant because they inspired the literary works or which are vividly described within them. However despite this broadranging interest in sites - both real and imaginary - associated with their favourite writers, studies suggest that it is in the homes and physical resting places where they tend to find the most meaning (Brown, 2015; Buell, 1989; Busby \& Shetliffe, 2013; Ousby,1990; Pocock, 1992; Watson, 2006). Smith (2003) divides the pilgrim into two further typologies - the fan expressing love for an author and those with a more academic interest. This reflects both the rational and emotional dimensions of literary touring as described by Reijnders (2011) in his analysis of Dracula-inspired tourists in Transylvania. In her work on film-induced tourism, 
Beeton suggests that there is a similar division between literary tourists and associated mediainspired visitors - stating that 'the main difference between literary and film tourism is that, in relation to the former, visitors often go to the regions that relate personally to the writer (such as place of birth or death), whereas film tourists visit the sites portrayed' (Beeton, 2005, p. 52). In this analysis, Beeton would seem to be suggesting that there is a gap between the more elite or serious-minded biographically inspired literary tourist and the more imaginatively driven media tourist. In this present paper, it is proposed that there are visitors who combine both impetuses.

Thus, although much of the academic research on dedicated literary tourists concentrates on the figure of the pilgrim visiting well-marked sites and authorial shrines, it is also fruitful to depart from this and explore the relationship between the process of reading and subsequent visitation. Indeed, as Laing and Frost suggest (2012), it is the very act of reading that prepares us for travel as we learn how to see places through the books we read. They argue that much literature is about travel, either explicitly or by the transformative power of the text. The popular concept of 'armchair travel' underscores the link between reading and transport in both its meanings. This link seems to be particularly prevalent in children's fiction which predisposes the adult to nostalgic travel in later life. In his research on tourists to Catherine Cookson Country in South Tyneside, UK, Pocock comments that these keen readers of Cookson's work 'bring with them eyes already prepared to see' (Pocock, 1992, p. 240). This blurring of the literary and real worlds reflects the "worldliness of the text and the textuality of the world' (Crang, 2003, p.1) and the fact that to keen readers, literary places may feel more real within their imaginations than they ever do in the physical world (Steibel, 2004).

Therefore, in attempting to go beyond the figure of the pilgrim, this research focuses on the literary enthusiast as tourist and attempts to understand the tourist activities of these readers 
and the way they utilise the touring experience. Several conceptual frameworks have been offered to try to understand the relationship between literary visitor and the locations themselves and each of these is predicated on the idea that the literary-inspired traveller "participates in the narrative creation of place" (Donaldson et al., p. 303). Herbert (2001) applies Johnson's (1986) concept of circuits of culture to the study of the production and consumption of literary place, noting that the texts created for visitors by site mangers may not be read in the ways intended, thus giving agency to visitors in literary settings who will interpret a site through the lens of their own knowledge and experience. The official interpretation becomes transformed through its consumption by visitors who bring new perspectives to the message. These transformed meanings are reworked into new narratives, hence the circular nature of the model. Similarly, Chronis (2005) and Fox (2008) emphasise the role of the visitor in producing meaning and their concept of co-construction emphasises the creation of a narrative in the present time. Aligned to the performance turn in tourist studies (Edensor, 2001; Johannesson, 2005), the co-construction of the literary tourism experience occurs where the visitor is an active participant in the production of the experience and its setting. Reijnders (2010) also emphasises the active nature of the relationship between visitor and toured setting, in this case, highlighting the role of specific nodes and reference points known to the literary informed tourist. Thus, his lieux d'imagination builds on Nora's (1984-92) lieux memoire in historic research which analyses the role of objects in creating memories. Lieux d'imagination replace the role of memory with that of imagination and these settings "are physical points of reference, such as objects or places which, for specific groups in the society, provide the opportunity to construct and subsequently cross the symbolic boundary between an imagined and a real world" (Reijnders, 2010, p. 40). These are useful frameworks which utilise a range of social science perspectives in exploring the active role of the literary tourist but, because of the contingent 
nature of literary touring and the act of reading, the authors sought a research paradigm that was more closely aligned to literary theory. Such approaches to the study of literary tourism are surprisingly scarce. Tribe and Liburd (2016) encourage the wider use of the humanities and arts (including literature) to provide critical approaches to tourism as a 'complex, worldmaking phenomenon and practice through which (inter-) cultural understandings and expression unfold' (2016, p.48) and Laing and Frost (2012, p. 17) note that mainstream tourism studies have under-utilised wider theories from literary studies, sociology, history folklore and geography - all of which would be illuminating to the study of books and travel. More specifically, Ryan, Zhang, Gu \& Song (2009) note with surprise that, as a research field so consonant with reading, literary tourism studies have seldom made use of literary criticism. The authors therefore were open to analysing the findings of the current research within the context of literary theory and to explore the relationship between the practices of reading and the lived experience of the literary setting. The literary theory of concretisation was identified as a potentially fruitful concept. This concept is aligned to the wider reception theory in literary studies which first originated from the work of Hans-Robert Jauss and Wolfgang Iser in the 1960s, being further developed by Hall in 1973. Reception theory was particularly influential in Germany and the US and is regarded as a key concept within postmodernism (Machor \& Goldstein, 2001). This theory views the literary text from the perspective of the reader/consumer and in doing so, attempts to move the discipline of literary criticism away from the scholarly accumulation of authorial facts and analysis of technical expertise towards an emphasis on the experience of the reader. The Polish philosopher Roman Ingarden first used this concept of concretisation to explain the role of the reader in realising a text as a literary work of art (Ingarden, 1973).

The term therefore describes the act of reading which transforms the virtual literary text into something more tangible - that is, an imaginatively realised product (Valdez 1993), which 
evolves from being an artistic to an aesthetic construct through the act of being read (Ingarden, 1973). No character or event can be exhaustively portrayed in a novel, for example, and it is the reader's job to flesh out the details, and actualise the potential within the literary text. Indeed, it is the very gaps in the narrative that engage the reader as they work with the text to make meaning (Mitscherling, 2005). Hermeneutics then suggest that each reader interprets the text in a different way depending on their individual internal and external context. Aligning the practice of literary touring to the concept of concretisation extends the role of the visitor whilst simultaneously underpinning the contribution that the literary tourism experience makes to the realisation of the text itself. Interestingly, Ingarden (1973) also occasionally refers to this concretisation as co-creation between the author and the reader and this accords with contemporary ideas on touristic co-creation where the visitor is no longer personified as a passive consumer of goods and services but rather as an active creator of their own experiences in partnership with destinations and tourism producers (Campos, Mendes, Valle \& Scott, 2015). Both ideas assume the notion of the active consumer and in this paper concretisation is viewed as a type of co-creation where the focus is less on the relationship between the visitor and the tourism suppliers/operators, and more concentrated on the visitor's engagement with the text and their own imaginative realisation within the literary setting.

\section{Methodology}

This research is underpinned by the interpretivist paradigm and is a product of the recent critical turn in tourism studies which moves tourism 'beyond questions of management and governance to that of reclaiming the world for humanity' (Ateljevic, Morgan \& Pritchard, 2013, p. xxxviii). Goodson and Phillimore (2004, p. 4), in their volume on qualitative research in tourism, opine that "qualitative approaches offer a great deal of potential, much of which remains largely untapped, for helping us understand the human dimensions of society, 
which in tourism include its social and cultural implications". This study is interpretivist in nature as it is focusses on the meaning created by respondents and is informed by the researchers' own experience (Hollinshead, 2006). Thus, the research design for this study was influenced by the researchers' observations of their own literary tourism predilections and experiences. These considerations alerted the researchers to the possibility of a type of literary tourism experience that was self-generated, internally produced and where satisfaction lay in the successful identification of literary settings in real places. This perception led to a research design which involved a group of self-confessed literary enthusiasts who were chosen to enable the further exploration of the theme. This opportunistic sample of literary fans was derived from a group of delegates attending a specialist literary conference in Bristol, UK in July 2014. The conference explored 'Twentieth century schoolgirls and their books' and the respondent group all had an interest in children's fiction of this period. Access to this convenience sample was permitted as one of the researchers was a conference delegate and could gather data in a way which was naturalistic and relatively unobtrusive. The sample group is highly selective and comprised of respondents with specialist literary interests. Therefore, a qualitative survey instrument was developed to capture data on these readers' literary tourism activities, trip planning habits and information sources along with basic demographic information. It also included several open-ended questions exploring motivations for trips and the feelings experienced when travelling in search of literary themes and locations.

This type of survey has been used in other studies exploring literary tourists' motivation (for example Busby \& Shetliffe, 2013; Pocock, 1992; Ryan et al., 2009) and the less-structured, more open approach to survey design taken in this research is regarded as being appropriate for small scale, exploratory studies. As respondents are given freedom to express themselves, it is considered that the accuracy of responses could be expected to be high although the lack 
of specific guidance in answering such questions may result in less truthful responses (Brotherton, 2008). However, one of the researchers attended the conference and could introduce the study to the delegates before the questionnaires were then distributed for selfcompletion. Although there are problems inherent in self-completion (not least of all the impact on response rate), the researchers wanted respondents to have time during the two-day conference to reflect on their responses. The highly selective nature of the respondent group and the assumption that, as delegates of a literary conference, they would be well-read and expressive, gave the researchers confidence that those who undertook to complete the questionnaire would do so fully. That confidence was borne out. From a delegate body of 91, thirty surveys were completed; twenty-seven were returned to the researcher on site and two by email, one by regular mail. The returned questionnaires in all cases were fully completed with detailed, rich responses being offered in the open-ended questions. Content analysis was used to study this data as it is an appropriate method for analysing tourism related texts (Hannam \& Knox 2005; Botterill \& Platenkamp, 2012) and as a method in the social sciences in general, is seen to have the advantages of transparency, flexibility and unobtrusiveness (Bryman \& Bell, 2011). However it must also be noted that, although decisions on what aspects of content to focus upon will be derived to a certain extent form the academic literature, they will also be researcher-driven and therefore subjective.

The survey gathered data on the age and occupation of the respondents, and a closed question was asked to ascertain whether they had ever travelled to visit literary locations. There then followed two questions designed to find out the following:

1. Who they travelled with

2. How they researched their trip. 
The subsequent section asked respondents to indicate the primary and secondary reasons for their literary inspired travel from a list of five motivations generated from existing studies on literary tourists where these reasons for literary visits appeared to be clearly delineated. These included motivations based on the concept of pilgrimage, interest in authorial biography, engagement with fictional settings and paying respect to a favourite writer (Brown, 2016; Busby \& Shetliffe, 2013; Herbert, 2001). Respondents were asked to nominate two motivations, both primary and secondary. There are of course limitations to using closed categories and in recognition of this, an open 'other' response option was provided.

The survey ended with two open-ended questions asking the respondents to describe their experiences of recent literary trips and to comment on perceived differences between independent and organised trips. The questions were framed in a general manner to encourage a more free-flowing response. Thus, the two open ended questions were as follows:

1. Could you describe a recent experience of visiting a literary site?

2. What is/would be the difference (if any) between planning your own trip and going on a pre-organised one?

The respondents gave much detail on both open-ended questions (ranging between 100-300 words per response) and content analysis commenced with 'open coding' (Strauss \& Corbin 1998, p. 62) of the responses which allowed the researchers to break down, examine, compare and begin to categorize the materials for thematic analysis. This approach to analysing qualitative data generated by respondents is widely used in tourism research and has been applied in literary tourism studies, for example by Es and Reijnders (2016) in their analysis of the motivations of crime-fiction tourists and by Jiang and $\mathrm{Xu}$ (2016) in their evaluation of writings and comments left by visitors at a literary tourism site. This method of 
'identifying, analysing and reporting patterns (themes) within data' (Jiang \& Xu, 2016, p. 5) allowed the very rich and often emotive responses to be analysed in a manner that did not compromise the depth and nuance of the material.

The initial analysis was framed by responses to the survey questions on methods of trip planning and motivation for literary travel where the centrality of the books themselves was evident. Alerted to this, the researchers undertook counts of keywords and references associated with books/literary texts and with authors to ascertain the relative dominance of these themes within the trip descriptions. Items counted included the words book/s, series, text/s, author, writer/s and specific authors' names. The association of authors with their works, literary settings and biographical sites were also noted.

Thereafter a more inductive approach was taken and a further close reading of the responses and subsequent open coding of the material revealed several categories which allowed for further thematic clustering and analysis. Eight separate codes were developed and grouped under three themes which formed the basis for the discussion below. Inter-coder reliability was ensured by the checking of codes within the researcher team to ensure consistency and stability. As Neuendorf (2002) notes, "given that a goal of content analysis is to identify and record relatively objective (or at least intersubjective) characteristics of messages, reliability is paramount..." (p. 141). Thus, inter-coder checking contributed to the rigour of the research.

The findings presented below have been derived from a small sample group that is highly selective and comprised of respondents with very specific literary interests. This clearly has limitations for the generalisability of the findings to the wider literary visitor but the authors' intentions were to deliberately focus on these specialist readers to explore specific aspects of literary tourism which may go beyond the notion of the pilgrim. In focussing on a more 
extreme example of the literary visitor/reader, the researchers hoped to explore a form of tourism activity that shares much with the traditional figure of the literary pilgrim but in its emphasis on the act of reading as a means of realising and appreciating the literary location, goes beyond that established trope.

\section{Research findings and analysis}

\subsection{Introduction}

The results discussed below present us with a very specific picture of the bibliophile as traveller. Having surveyed a group of keen readers to uncover their motivations and preferences in relation to literary trips, we found that our typical respondent was a mature woman in the academic/professional field who was keen to organise her own trips and travel alone or with like-minded companions. Serious about both their reading and their literary quests, they plan and prepare assiduously using the books as a primary resource but also rely on information exchanges from within their own communities. These travellers only use preorganised tourist experiences where absolutely necessary, preferring to make their own arrangements and use their own knowledge to track down locations

4.2 Demographic profile, trip planning and motivations

The conference delegate respondents were found to have all visited a site because of its literary associations and so all the completed surveys could be used. Respondents were almost exclusively women (with one male respondent in the sample). This is perhaps unsurprising, given the themes of the conference which, although it explored wider children's literature, did tend to focus on fiction aimed at girls. However, the predominance of women does also reflect the profile found in wider literary tourism research (for example, BonniotMirloup, 2016; Busby \& Shetliffe, 2013; Earl, 2008; Pocock, 1992). The delegates were a mature group with nearly half being 65 and above and the remainder largely in age range 45- 
64 with only three in age range 25-44. Most marked was the profile of their occupations with a third of the group being teachers or lecturers, five of the group, librarians and one a writer. Three were retired and the rest were from professional backgrounds that included psychiatry, accountancy, architecture, law, the arts and human resource management. Given the nature of the conference, the preponderance of occupations in the field of education and literacy is to be expected. However, this very particular profile has a precedent in the literature: Reijnder's research on literary visitors on a Dracula tour in Romania uncovered a 'relatively large proportion of students, teachers and retirees' (Reijnders, 2011, p. 236), Earl's study of literary tourists on the Arthurian trail in England found that they were 'female, retired and most of them had 'literary' backgrounds, having either worked in academia, teaching or as librarians' (Earl 2008, p. 403). Other literary tourism studies reflect the predominance of professional and managerial/white collar professions and high incidences of degree-level education within samples (Busby \& Shetliffe, 2013; Herbert, 2001).

The first set of questions asked with whom the respondents undertook their most recent literary trip and how they researched and prepared for it. Most trips were made as individuals or with friends and family with only four stating that they had travelled as part of an organised group. They reported that to arrange their trips, all but two had used the books themselves as their primary inspiration. Literary fan clubs were the second most popular resource for planning trips with more generic tourist information websites and search engines being used as secondary aids.

The survey continued with a question on the respondents' primary and secondary motivations for undertaking a literary themed trip. They were offered five potential motivations based on existing studies of literary tourists and pilgrims (Brown, 2015; Herbert 2001; Smith, 2003). These motivations reflected interest in authorial biography and the more imaginative aspects of their literary products and the responses are shown in Table 1. 
[Insert Table 1 about here]

As can be seen, by far the most popular motivation chosen was that of exploring where a book was set with the next most stated option being to relive imagined scenes. There was a clear connection between these two terms with 16 respondents stating them together. The respondents seem to be inspired by the idea of visiting a specific location to imagine scenes delineated in the book. Very few seemed to be motivated by a desire to see places associated with the life of the author or to add to their factual knowledge and the notion of pilgrims paying respect to their favourite authors as in Brown (2015) was not considered. This shows a marked orientation towards the text itself, both as a planning resource and as inspiration for the visit.

\subsection{Experiences and themes of literary trips}

The subsequent questions requested that respondents describe a recent literary-inspired trip and provide their thoughts on organised travel versus independent trips - they did this at length and with feeling. Literary visits ranged from sites in England, Wales, Scotland, the Channel Islands, Austria, Switzerland, France, Israel, USA and Canada. Authors' works explored included those of Elinor Brent-Dyer, Elsie J. Oxenholme, L.M. Montgomery, Arthur Ransome, Russell Thorndyke, Thomas Hardy and P.G. Wodehouse. The respondents' reported motivations for visiting literary sites and their reliance on novels and texts as planning resources, as discussed above, framed the researchers' initial content analysis of these open-ended responses. In particular, the researchers carried out counts of keywords and references associated with books/ literary texts and with authors to ascertain the relative dominance of these themes within the trip descriptions. These are represented in Table 2.

[Insert Table 2 about here] 
The responses had a very clear leaning towards texts with the words 'book' 'books' and 'series' being mentioned 30 times. The words 'author' and 'writer' only appeared twice. Respondents named their inspirational texts and 21 specific book titles were given. Authors were not ignored in their reports with writers being named on 20 occasions. However, it became clear that authors were being mentioned largely in relation to their works (there were 15 occasions where this happened). There were only five examples of respondents mentioning authors in relation to biographical settings such as birthplaces, homes or burial sites. This sets this sample group somewhat apart from the stated motivations of literary pilgrims who have been found to have specific interests in places associated with writers' lives (Brown, 2015; Buell, 1989; Busby \& Shetliffe, 2013; Pocock 1992; Watson, 2006).

After this initial analysis, a further close reading of the responses was undertaken and open coding of the material revealed eight codes which were grouped under three themes (Table 3). These themes echo the importance of the literary text itself as a primary source of inspiration and a practical resource for these visitors in tandem with their valuing of knowledge and expertise. Thus, the theme of Co-creation between visitor and text illustrates the ways in which these visitors utilise the text in order to produce the experience of the visit, the themes of The role of imagination in the literary trip experience underpins the imaginative realisation of the visit and includes the role played by emotion and the close link between their experience of the text and their lived experience of the place itself. Finally the third theme of Community of knowledge emphasises the importance of expertise and likeminded companionship to these visitors. These linked themes, underpinning as they do the inter-relationship of place and imagination, active engagement with the text and the role of personal knowledge, advance the use of the concept of concretisation to interpret the particular experiences of these bibliophile visitors. 
The themes of Co-creation between visitor and text are illustrated through the following extracts which emphasise the centrality of the literary text as a key tool in planning and experiencing a literary visit, and highlight the diligence of the preparations. Firstly, it's evident that the respondents (re)-read favourite texts pre-visit to prepare for the trip (code 1:re-reading before trip): Thus respondents noted that "I re-read (and stick copious Post It notes on) the relevant books, buy maps and plan walking routes" (Respondent 11) and "I did my own re-reading first and went armed with a map with relevant sites marked on it" (Respondent 29). Another refers directly to the author whose work she specifically uses in her trip planning: "I used the books of EJO (Elsie J. Oxenham) to help plan" (Respondent 12). Sometimes the text needs to be studied again before it gives up its locational secrets as Respondent 1 notes when she "re-read the book for clues in the text". Thus, for these literary visitors, the text is the departure point for the visit and their primary source of reference. Respondents also referred to the research and preparation undertaken (Code 6: Preparation/research) in such statements as "need to do homework before travelling in order to appreciate what you are seeing" (Respondent 23). Despite the duty inferred in the term 'homework', visitors seem to take pleasure in “...the fun of the research” (Respondent 26) commenting that "my daughter and I enjoy planning our own trips" (Respondent 13). Respondents are therefore committed and serious in their preparations and clearly see this as an important step towards the overall enjoyment of the trip.

There is also an emphasis on the respondents using their own knowledge in tandem with the texts to find locations in the field. The concept of the pleasure of the hunt using literary clues (Code 5: hunting /clues) is very evident with respondents enjoying using their own personal knowledge and the texts themselves as sources of clues to locations: no one mentioned that they followed a literary trail, published itinerary or guidebook for example. Instead we find statements such as "local observations enabled us to identify particular scenes" (Respondent 
1) and a visitor shunned commodified sites as she "walked to find places mentioned in the books but which are not obvious tourist attractions" (Respondent 18). One respondent "spent some time looking at the row of houses where her (Angela Thirkell's) grandparents lived trying to work out how they fitted the description in her book" (Respondent 28). The challenge of the hunt is obvious in such phrases as "my literary quests" (Respondent 11) where the tour is conceptualised as the pursuit of a treasured goal. We also hear of those who "enjoy the hunt of finding places and identifying them to own satisfaction...the thrill of discovery" (Respondent 13).

Figure 2 is a photograph that demonstrates a bibliophile experiencing the pleasure of the hunt at the 'dripping rock' in Achensee, Tyrol, Austria, a scene set in The Chalet School and Jo by Elinor Brent-Dyer.

\section{[Insert Figure 2 about here]}

These responses show an interesting denial of the assumed biographical leanings of the literary pilgrim in favour of the books themselves. There is some interest shown in authorial sites but most comments denote a strong link between the literary texts as a source of inspiration and preparation for the trip and as a repository of clues for tracking down locations. This emphasises the co-construction between reader and text that is a key aspect of concretisation. The touring reader uses the text and their associated knowledge to produce meaning and satisfaction within the literary setting. This type of traveller therefore avoids passive, themed settings in favour of active participation in the creation of the place narrative (Donaldson et al 2015), populating the gaps with their own knowledge and interpretation. These co-created spaces become points of reference or, lieux d'imagination (Reijnders 2010), where those with the necessary knowledge can bring together real and imagined worlds. 
The second theme is linked to the first in that it continues to explore the relationship between the reader and text within literary landscapes but in this theme, the role of the imagination is emphasised. This theme builds on the previous motif with its emphasis on the conflation of the act of reading with the subsequent experience of place and this finding illustrates the symbiotic relationship between the acts of reading and becoming a tourist which Laing and Frost (2012) believe is strong. The respondents referred often to their experience of destinations in relation to their reading of the associated texts, (Code 2: In-situ reference to text) as we see in the following description: "One day we walked up the Feilkopf and saw Pertisau below, looking just as it is described in The School at the Chalet. It makes me realise how good EBD (Elsie J. Oxenham) was at evoking a sense of place" (Respondent 7). Another visitor commented on how viewing the real-life location "helped establish a picture of the geography of the area in my mind" (Respondent 22). In describing the impact of the texts on her literary trip, one Respondent tells us that "my daily activities were very much dictated by events from the books" (Respondent 24). The congruence of these experiences clearly evokes positive reactions - Respondent 18 informs us that "it was a joy to see PEI (Prince Edward Island) and compare it to LMM's (L.M. Montgomery's) descriptions and Anne's reactions".

Also evident is the animation or imaginative peopling of the real scene before them which enhances, for respondents, the moment of visitation and the subsequent act of (re)reading: (code 6: Use of imagination). One visitor informs us that "I imagine scenes in the books as I visit them ("channelling" the characters' experiences)" (Respondent 11). Another respondent states that it's "great to be able to see places I had imagined - can now read books seeing the reality in my mind's eye" (Respondent 23). This is clearly a key aspect of the trip that these visitors expect to experience, for example one traveller explained that she preferred solo travel because it's "much easier to imagine stories on my own" (Respondent 
23). One respondent sums up her satisfaction with her visit as "I could imagine it all"

(Respondent 20). These responses very clearly indicate the strong relationship between the visit and the act of reading where the experience in situ is valued for what it can add to the interpretation of the text and its subsequent re-reading. Ryan et al (2009, p. 13) explain how readers feed their literary tourism experiences back into their understanding of the text and similarly, Ridanpää, (2011, p. 106) comments on the reciprocity of literature and place places are experienced through literature and novels are subsequently re-read in the light of the experience of the visit. A final aspect of this theme is the emotional response to the literary setting or experience (code 4: Emotional response): this code illustrates the emotional reaction that is clear in the recalling of literary trips. Although expert knowledge and factual accuracy are valued there is definitely a more emotional dimension to the experience too with language used to evoke excitement, reverence and being moved by the experience. One respondent explains how her literary knowledge allows her to feel "connected to a place" (Respondent 11) whilst another recounts that "I was excited to go and then on first sight was moved" (Respondent 4).

Emotion can be perceived in the following statements: "It was a joy to see Prince Edward Island" (Respondent 18); "I was quite emotional" (Respondent 29) and "very pleased to see actual place. Slight sense of déjà vu” (Respondent 19). Another demonstrated pilgrim-like reverence to an author (Brown ***) as she "put flowers on her grave" (Respondent 28). The sentimental role that literary connections play in visitors' lives is demonstrated by one respondent who states that she "found myself driving very out of the way just so that I could drive down the back of Coniston to catch a glimpse of the island for my Swallows and Amazons 'fix' (Respondent 20). There is a certain sense of nostalgia detected here locations associated with the books of childhood seem to evoke a particularly emotive response as Squire points out (1991). 
Children themselves are rarely voluntary literary tourists, preferring to inhabit the world of the story within their heads (Watson, 2006) but the adult is drawn towards a more tangible manifestation of this inward imagining, perhaps as a sentimental link back to childhood itself.

The third theme emerging from the content analysis is that which the researchers have termed a Community of Literary Knowledge and which comprises the codes of likeminded companionship (code 7) and expertise (code 8). Although these literary enthusiasts are very happy to travel alone to pursue their interests, they do also appreciate the knowledge of companions as sharing experiences and working together to find locations appears to be a significant part of the enjoyment. A respondent described how she "especially enjoyed being in the company of Chalet fans and discussing the books" (Respondent 27); another simply found it "fun to go with fellow enthusiasts" (Respondent 24) and another outlined the benefits of travelling with fellow fans who can share references - "went with a group of like-minded friends - can enjoy some 'this bit is where this happened" (Respondent 9). One respondent described how repeat visits with friends serves to enhance the understanding further - she took a "trip to Pertisau with like-minded friend. We have done the same visit several times before so charm of familiarity... although repetitious, I found that ideas and opinions are deepened" (Respondent 3). Even when travelling alone a visitor felt that she was accompanied by the literary characters in her mind - "I feel as if I have lots of company... as if I'm connected to a place through the ages" (Respondent 11). Not all company is likeminded however and a mother reminded us of the challenges of traveling with a teenager in the following response - "my daughter has not read any of these books and got very grumpy and fed up. 'It's all about you' she said" (Respondent 26). These responses indicate that our respondents prefer to travel alone or with kindred companions with whom they can share their searches and revelations. 
A second code associated with the theme of a community of literary knowledge is that of expertise. This was particularly evident where respondents were considering the benefits of organised group travel: safety, security and ease were not highlighted as perceived benefits but an organised tours would be considered valuable if it enhance knowledge. Thus "someone else's itinerary may give you ideas you hadn't thought of" (Respondent 7) thus allowing one to "find out things you didn't know beforehand" (Respondent 17). Respondent 7 commented that "A knowledgeable guide is always good" and Respondent 11 stated that they did value “expert knowledge.” [Insert Table 3 about here]

In considering these related themes it is proposed that, unlike the literary pilgrim who is often characterised as travelling to pay respects at various shrines linked to authorial biography, these readers are keen to locate fictional locations in the real world, shunning guidebooks for novels and authors' lives for imaginary locations. As discussed earlier, this impulse is akin to that of the film tourist or other media-based traveller who wishes to pin down the fictive within a concrete setting (Beeton, 2005; Gibson, 2006; O’Conner \& Kim, 2014) - what Tetley and Bramwell describe as "a desire to transcend the medium, to anchor in reality the dramas and characters that are fictional" (Tetley \& Bramwell, 2002, p. 156). Indeed, this desire seems particularly clear where a film tourist is visiting the site of a literary adaptation as Pennacchia (2015) explains in relation to adaptions of Jane Austen novels. She argues that Austen's descriptively sparse writing style is augmented by film and TV adaptations which allow the reader to 'visualize' a world that is otherwise conveyed through conversation. These same visitors may enjoy watching several different adaptations of a literary work and the repetition allows them to 're-live, in one more different way, similar emotions, thus reinforcing myth and storytelling' (Pennacchia, 2015, p. 264). Similarly, with this sample group, there is a sense of reliving the text but with these travellers, the literary journey is 
perceived as being correlative to the act of reading and these visitors will return to the texts with a renewed appreciation having visited the associated sites. It is their lived experience of the location which fleshes out the text for them. Gothie refers to this correlation in her analysis of Anne of Green Gables' visitors on PEI who see 'the 'external milieu' (toured location) as complementary to, and even a culmination of, the internal experience of reading" (2016, p. 12). Similarly, Ryan et al. (2009, p. 13) comment on how readers feed their literary tourism experiences back into their understanding of the text and Ridanpää, (2011, p. 106) emphasises the reciprocity of literature and place - places are experienced through literature and novels are subsequently re-read in the light of the experience of the visit. This impulse may be like that described by Watson in early days of non-biographical tourism where visitors sallied forth to find sites that may not exist outside of their fictive description - and that very process sent the reader back to the text itself (2006. p. 132). In the case of the readers surveyed here, there appears to be a sense that the touring experience is actively taken to supplement the act of reading itself. Robertson and Radford (2009) explore this further in their analysis of literary pilgrims where they analyse this figure from a reading theory, rather than a tourism studies, perspective - they describe this traveller as 'a truly fevered reader who seeks in a place of lost things the full promise of a once-felt reading' $(2009$, p. 206).

As discussed in the literature review above, the concept of concretisation is therefore offered as an explanation of the experience of these bibliophile travellers. Borrowed from literary theory and first used by Ingarden, this concept describes the process whereby the reader completes the gaps in the structure of a work of art by making concrete its 'places of indeterminacy' (Ingarden, 1973, p. 50). In short, the literary text is an amorphous concept until the act of reading turns it into something concrete (Valdez, 1993). In their literary quests, the surveyed readers were travelling to read and re-read - the books, the landscapes, 
the clues. Their lived experiences were then fed back into the act of reading the texts and brought them further into being as the proposed conceptual model in Figure 3.

\section{[Insert Figure 3 about here]}

This practice is what gives rise to such comments as 'I imagine scenes in the books as I visit them...channelling the characters' experiences' (Respondent 11) and 'I could imagine it all' (Respondent 20). In discussing the act of concretisation within literary theory, Adams (1964) talks about the interpreter of the work as an artist for whom "a concretisation is both a means of understanding the creator's work and a means of sustaining his own interpretation of that work" (Adams, 1964, p. 119). Examining this statement within the context of our bookloving travellers, we can see that the touring experience renders the imaginative work concrete which adds to the enjoyment and understanding of the literary text (e.g. "one day we walked up the Feilkopf and saw Pertisau below, looking just as it is described in The School at the Chalet. It made me realise how good Elinor Brent Dyer was at evoking a sense of place" Respondent 7). Subsequently, the concretisation augments and enhances the reader's own internal interpretation of the work which they carry with them after the visit has ended ("it helped establish a picture of the geography of the area in my mind" Respondent 22; "I can now read the books seeing the reality in my mind's eye" Respondent 23).

This research demonstrates the potential for applying literary theory to tourism studies and emphasises the congruence of these approaches to literary tourism. The analysis is limited by its relatively small number of respondents and their highly specialised nature making replicability difficult. However, in illustrating a niche group of special interest travellers and exploring their motivations to extend our understanding beyond the notion of the literary pilgrim this study has value and contributes to the growing body of theory within this field. 


\section{Conclusions}

This research explores a variety of literary tourism experience that is self-generated, internally produced and where pleasure lies in the successful identification of literary locations in real settings. With this emphasis on the internal experience of the external visit, it is clear that this specialist reader-tourist is not a potential consumer that is easily accessible to the tourism industry. However, the managerial implications of this research may lie in the value that could be had in hotels and other service providers in known literary destinations advertising on fan websites and targeting travellers through social media. The recognition of this visitor segment within the wider literary tourism market will also have a role to play in the marketing of relevant destinations. Nevertheless, the emphasis for the touring reader will remain on the independent application of knowledge in creating the literary setting. Future research is required to explore the lived travelling experiences of these readers in more depth perhaps by using a diary method to capture more detailed reports. This would be a particularly appropriate research approach given the expressiveness of the respondents and mobile technologies would allow immediate capture of experiences in the field.

This research aims to contribute to academic studies on literary tourism by focussing on the reader as tourist. There is a rich body of work on the literary pilgrim in search of inspiration and communion at shrines dedicated to writers and their works but the current researchers sought to explore the book-loving reader as potential traveller. The departure point for the research came from their own personal experiences of seeking out literary locations through a process of self-discovery rather than engaging with the sites and markers produced by the flourishing literary tourism industry. In surveying a group of self-confessed literary fans at a specialist conference, the authors confirmed that, for this particular group, engaging with organised tours and managed sites was not as attractive a proposition as seeking out places of literary association themselves, using the texts alone for clues. This group were much more 
text than author focussed and felt that the experience was more valued if it was hard-earned. Although studies on literary pilgrims provide important insights into the disciplined and devoted literary traveller, the concept of a pilgrim worshipping at a demarcated shrine was seen as being a less useful way of conceptualising this group of readers' experiences. Instead, the literary theory of concretisation is offered as a means of exploring their touring experience and its relationship to the act of reading itself. In using this approach, it was found that the bibliophile travels to augment her reading experience - to complete the gaps, solidify the imaginary and ultimately, to bring the lived experience of these fictional settings back into the text. As they exhibit many of the characteristics of the literary pilgrim, the researchers do not propose that their survey group constitutes a new typology of literary tourist with concomitant needs that can be met by the contemporary literary tourism industry. However, they do propose that the research presented here extends the concept of the literary pilgrim and explores a type of bibliophile traveller who is focussed on the experience of reading the text and appreciates how a material setting can contribute to its imaginative construction. Thus the research has advanced literary tourism studies by re-conceptualising the literary pilgrim. This figure is no longer simply characterised as an ardent and wellinformed frequenter of authorial shrines, differentiated from the generalist visitor in terms of purposefulness and knowledge but can now also be appraised as a lover of texts who uses these imaginative products to co-create layered literary locations, accessible only to those with the textual insight to fill in the gaps and render these spaces legible. Thus, conceptualising the literary trip as an act of concretisation highlights the interdependence of texts and travels and reminds us of the important role of dreaming and imagining in the realisation of tourist trips. 


\section{References}

Adams, K. (1964). Notes on Concretization. The British Journal of Aesthetics, 4(2), p.115.

Aitchison, C., MacLeod, N.E., MacLeod, N.E. and Shaw, S.J. (2002). Leisure and tourism landscapes: Social and cultural geographies. London: Routledge.

Ateljevic, I., Morgan, N. and Pritchard, A. eds., 2013. The critical turn in tourism studies:

Creating an academy of hope (Vol. 22). Routledge.

Beeton, S. (2005). Film-induced tourism. Buffalo, Toronto: Channel View.

Bonniot-Mirloup, A. (2016). “Tourism and writers' houses, in between places and

literature”, Via@, 2016-1(9), Retrieved April 12, 2017, from Via Web site:

http://viatourismreview.com/2016/10/tourisme-et-maisonsdecrivain

Booth, A. (2016). Homes and haunts: Touring writers' shrines and countries. Oxford: Oxford University Press

Botterill, D., \& Platenkamp, V. (2012) Key concepts in tourism research. London: Sage.

Brown, L. (2015). Tourism and pilgrimage: paying homage to literary heroes. International Journal of Tourism Research DOI: 10.1002/jtr.2043

Brown, L. (2016). Treading in the footsteps of literary heroes: an autoethnography. European Journal of Tourism, Hospitality and Recreation. 7(2), 135-145

Brooker, W. (2005). "It Is Love" The Lewis Carroll Society as a Fan Community. American Behavioral Scientist, 48(7), 859-880.

Brotherton, B. (2015). Researching hospitality and tourism. London: Sage.

Bryman, A. and Bell, E. (2011) Business research methods, 3rd edn. Oxford: Oxford University Press. 
Buchmann, A. (2006). From Erewhon to Edoras: tourism and myths in New Zealand. Tourism Culture \& Communication, 6(3), 181-189.

Buell, L. (1989). The Thoreauvian pilgrimage: The structure of an American cult. American Literature, 61(2), 175-199.

Burger, P. (2015). Women's groups and the rise of the book club. Retrieved April 12, 2017, from JSTOR Web site: https://daily.jstor.org/feature-book-club/

Busby, G., \& Shetliffe, E. (2013). Literary tourism in context: Byron and New stead Abbey. European Journal of Tourism, Hospitality and Recreation. 4(3), 5-45.

Busby, G., Brunt, P., \& Lund, J. (2003). In Agatha Christie country: Resident perception of special interest tourism. Tourism, 51(3), 287-300.

Butler, R. (1986). Literature as an influence in shaping the image of tourist destinations: A review and case Study. Canadian studies of parks, recreation and foreign lands, 111-132.

Buzard, J. (1993). The Beaten Track: European tourism, literature and the ways to culture 1800-1918, New York: Oxford University Press.

Campos, A.C., Mendes, J., Valle, P.O.D. and Scott, N. (2015). Co-creation of tourist experiences: A literature review. Current Issues in Tourism, 1-32.

Chronis, A. (2005). Coconstructing heritage at the Gettysburg storyscape. Annals of tourism research, 32(2), 386-406.

Crang, M. (2003). Placing Jane Austen, displacing England: touring between book, history and nation. In S. R. Pucci \& J. Thompson (Eds.), Jane Austen and Co.: Remaking the past in contemporary culture (pp.111-132). New York: SUNY Press. 
Donaldson, C., Gregory, I.N., \& Murrieta-Flores, P. (2015). Mapping 'Wordsworthshire’: a GIS study of literary tourism in Victorian Lakeland. Journal of Victorian Culture, 20(3), $.287-307$.

Earl, B. (2008). Literary tourism Constructions of value, celebrity and distinction. International Journal of cultural studies, 11(4), 401-417.

Edensor, T. (2001). Performing tourism, staging tourism: (Re) producing tourist space and practice. Tourist Studies, 1(1), 59-81.

Es, N.V., \& Reijnders, S. (2016). Chasing sleuths and unravelling the metropolis: analyzing the tourist experience of Sherlock Holmes' London, Philip Marlowe's Los Angeles and Lisbeth Salander's Stockholm. Annals of Tourism Research, 57, 113-125.

Fawcett, C., \& Cormack, P. (2001). Guarding authenticity at literary tourism sites. Annals of Tourism Research, 28 (3): 686-704.

Fox, R. (2008). Marin Drzic: A case for Croatian literary tourism. Journal of Heritage Tourism 3(2), 138-153.

Gentile, R., \& Brown, L. (2015). A life as a work of art: Literary tourists' motivations and experiences at il Vittoriale degli Italinai. European Journal of Tourism, Hospitality and Recreation. 6(2), 25-47.

Gibson, S. (2006). A seat with a view Tourism, (im) mobility and the cinematic-travel glance. Tourist Studies, 6(2), 157-178.

Gothie, S.C. (2016). Playing “Anne”: Red braids, Green Gables, and literary tourists on Prince Edward Island. Tourist Studies, 16(4), 405-421.

Hamilton, C., \& Seale, K. (2014). Great expectations-making a city of literature. Meanjin, 73(1), 142-151. 
Hannam, K. \& Knox, D. (2005). Discourse analysis in tourism research: A critical perspective. Tourism Recreation Research, 30(2), 23-30.

Hendrix, H. (2009). From early modern to romantic literary tourism: A diachronical perspective. In N. Watson (Ed.), Literary tourism and nineteenth-century culture (pp. 1324). Basingstoke: Palgrave.

Herbert, D.T. (1996). Artistic and literary places in France as tourist attractions. Tourism Management, Vol 17, no.2, 77-85.

Herbert, D. (2001). Literary places, tourism and the heritage experience. Annals of Tourism Research. Vol. 28, No. 2, 312-333.

Hollinshead, K. (2006). The shift to constructivism in social inquiry: Some pointers for tourism studies. Tourism Recreation Research, 31(2),43-58.

Hoppen, A., Brown, L. and Fyall, A. (2014). Literary tourism: Opportunities and challenges for the marketing and branding of destinations? Journal of Destination Marketing \& Management, 3(1), 37-47.

Ingarden, R. (1973). The Literary work of art, trans. George G. Grabowicz, Evanston: University of Illinois.

IPA (2016) International Publishers Association Annual Report 2016. Retrieved April 12, 2017, from IPA Web site: https:// www.internationalpublishers.org/news/industrynews/454-ipa-releases-annual-report-and-global-publishing-statistics

Jiang, L., \& Xu, H. (2016). The growth of literary places in ancient town tourism destinations: based on the theories of Bourdieu, Danto and Dickie. Journal of Tourism and Cultural Change, 1-16. 
Johannesson, G.T. (2005) Tourism translations: Actor-network theory and tourism re-search. Tourist Studies, 5(2), 133-150.

Keith, W.J. (1969). Thomas Hardy and the Literary Pilgrims. Nineteenth-Century Fiction, 24(1), 80-92.

Laing, J., \& Frost, W. (2012). Books and Travel: Inspiration, quests and transformation, Bristol: Channel View

Lester, J.A., \& Scarles, C. (2016) Mediating the tourist experience: From brochures to virtual encounters. London: Routledge

Light, D. (2017). The undead and dark tourism: Dracula tourism in Romania. In G. Hooper \& J.J. Lennon (Eds.), Dark tourism: Practice and interpretation (pp.121-133). Abingdon: Routledge

Lipovšek, E., \& Kesić, S. (2015). Commodification of culture in fiction-induced tourism. TIMS. Acta, 9(2), 105-113.

Machor, J.L. and Goldstein, P. (Eds.). (2001). Reception study: From literary theory to cultural studies. Psychology Press.

Mackay, P., \& Pittock, M. (2011). Beyond Text: Burns, Byron and their material cultural afterlife. The Byron Journal, 39(2), 149-162.

Macleod, D. (2009). Scottish Theme Towns: have new identities enhanced development? Journal of Tourism and Cultural Change 7(2), 133-145

MacLeod, N., Hayes, D., \& Slater, A. (2009). Reading the landscape: the development of a typology of literary trails to inform experiential design. Journal of Hospitality Marketing and Management, 18, 154-172. 
Mitscherling, J. (2005). Concretization, literary criticism, and the life of the literary work of art. In A. Chrudzimski (Ed.), Existence, culture and persons: The ontology of Roman Ingarden (pp.137-158). Piscataway, N.J.: Transaction Books.

Müller, D.K. (2006). Unplanned development of literary tourism in two municipalities in rural Sweden. Scandinavian Journal of Hospitality and Tourism, 6(3), 214-228.

Neuendorf, K. A. (2002). The content analysis guidebook. Thousand Oaks, CA: Sage.

Novelli, M. (Ed.). (2005). Niche tourism: contemporary issues, trends and cases. London: Routledge.

O'Connor, N., \& Kim, S. (2014). Pictures and prose: exploring the impact of literary and film tourism. Journal of Tourism and Cultural Change, 12(1), 1-17.

O'Neill, K., Butts, S., \& Busby, G. (2005). The Corellification of Cephalonia tourism. Anatolia, 16(2), 207-226.

Ousby, I. (1990). The Englishman's' England: Taste travel and the rise of tourism. Cambridge: Cambridge University Press.

Pennacchia, M. (2015). Adaptation-induced Tourism for Consumers of Literature on Screen: the Experience of Jane Austen Fans. Almatourism-Journal of Tourism, Culture and Territorial Development, 6(4), 261-268.

Philips, D. (2011). Mapping literary Britain: Tourist guides to literary landscapes 1951-2007. Tourist Studies 11(1), 21-35.

Phillimore, J., \& Goodson L. (Eds.). (2004). Qualitative research in tourism: Ontologies, epistemologies and methodologies. London: Routledge. 
Pocock, D. (1992). Catherine Cookson country: Tourist expectation and experience. Geography, 236-243.

Reijnders, S. (2010). Places of the imagination: An ethnography of the TV detective tour. Cultural Geographies, 17(1), 37-52.

Reijnders, S. (2011). Stalking the count: Dracula, fandom and tourism. Annals of Tourism Research, 38(1), 231-248.

Ridanpää, J. (2011). Pajala as a literary place: in the readings and footsteps of Mikael Niemi. Journal of Tourism and Cultural Change, 9(2), 103-117.

Robertson, J.P., \& Radford, L.A. (2009). The private uses of quiet grandeur: A meditation on literary pilgrimage. Changing English, 16(2), 203-209.

Robertson, M., \& Yeoman, I. (2014). Signals and signposts of the future: Literary festival consumption in 2050. Tourism Recreation Research, 39(3), 321-342.

Robinson, M. (2002). Reading between the lines: Literature and the creation of touristic spaces. Current Writing: Text and Reception in Southern Africa, 14(1), 1-28.

Ruiz Scarfuto, R. (2013). Literary routes: contributions to natural/cultural heritage tourism. How landscape transforms literature and tourism. AlmaTourism: Journal of Tourism, Culture and Territorial Development, 4(8), 1-18.

Ryan, C., Zhang, Y., Gu, H., \& Song, L. (2009). Tourism, a classic novel and television: The case of Cao Xueqin's Dream of the Red Mansions and Grand View Gardens, Beijing. Journal of Travel Research 48(1), 14-28.

Santesso, A. (2004). The Birth of the birthplace: bread Street and literary tourism before Stratford, ELH (71), 377-403. 
Saretzki, A. (2013). Literary Trails, Urban Space and the Actualization of Heritage. Almatourism-Journal of Tourism, Culture and Territorial Development, 4(8), 61-77.

Smith, K.A. (2003). Literary enthusiasts as visitors and volunteers, International Journal of Tourism Research 5, 83-95.

Smith, Y. (2012). Literary tourism as a developing genre: South Africa's potential (Doctoral dissertation, University of Pretoria).

Squire, S.J. (1991). Meanings, myths and memories: literary tourism as cultural discourse in Beatrix Potter's Lake District (Doctoral dissertation, University of London).

Stiebel, L. (2004). Hitting the hot spots: Literary tourism as a research field with particular reference to KwaZulu-Natal, South Africa. Critical Arts, 18(2), 31-44.

Strauss, A.L., \& Corbin, J. (1998). Basics of qualitative research. 2nd edn., Thousand Oaks, CA: Sage

Tetley, S., \& Bramwell, B. (2002). Tourists and the cultural construction of Haworth's literary landscape. In M. Robinson \& H. Andersen (Eds.), Literature and tourism: Essays in the reading and writing of tourism (pp. 155-170). London: Thomson International.

Towner, J. (2002). Literature, tourism and the Grand Tour. In M. Robinson \& H. Andersen (Eds.), Literature and tourism: Essays in the reading and writing of tourism (pp. 226-238). London: Thomson International.

Tribe, J., \& Liburd, J.J. (2016). The tourism knowledge system. Annals of Tourism Research, $57,44-61$.

Troost, L. (2006). Filming tourism, portraying Pemberley. Eighteenth Century Fiction, 18(4), 477-498. 
Valdez, M.J. (1993). Concretisation. In I.R. Masaryk, (Ed.), Encyclopaedia of contemporary literary theory (pp.527-8). Toronto: University of Toronto.

VisitEngland (2017) The Year of Literary Heroes. Retrieved April 5, 2017, from Visit England Web site: https://www.visitbritain.org/year-literary-heroes-2017

Wallace, C. (2009). Yeats' country and 'Yeats country': conceptualising literary spaces. Journal of tourism and cultural change 7(1), 48-60.

Wang, H.J., \& Zhang, D. (2017). Comparing literary tourism in Mainland China and Taiwan: The Lu Xun Native Place and the Lin Yutang House. Tourism Management, 59, 234-253.

Watson, N. (2006). The literary tourist: Readers and places in romantic and Victorian England. Basingstoke: Palgrave.

Watson, N. (Ed.). (2009). Literary tourism and nineteenth-century culture. Basingstoke: Palgrave.

Westover, P.A. (2012). Inventing the London of literary tourists: Walking the Romantic city in Leigh Hunt's “Wishing-Cap” Essays. European Romantic Review, 23:1, 1-19, DOI:10.1080/10509585.2012.639180

Yiannakis, J.N., \& Davies, A. (2012). Diversifying rural economies through literary tourism: a review of literary tourism in Western Australia. Journal of Heritage Tourism, 7(1), 3344. 
Table 1

Motivations for visiting literary locations

\begin{tabular}{|l|c|c|c|}
\hline Motivations & Total & Primary & Secondary \\
\hline $\begin{array}{l}\text { To explore somewhere that } \\
\text { a book or series was set }\end{array}$ & 26 & 19 & 7 \\
\hline $\begin{array}{l}\text { To relive imagined scenes } \\
\text { in real settings }\end{array}$ & 17 & 4 & 3 \\
\hline $\begin{array}{l}\text { To see places associated } \\
\text { with a writer's life }\end{array}$ & 7 & 0 & 2 \\
\hline $\begin{array}{l}\text { To add to your factual } \\
\text { knowledge of the author }\end{array}$ & 2 & 0 & 0 \\
\hline $\begin{array}{l}\text { To pay your respects } \\
\text { to/commemorate a } \\
\text { favourite author }\end{array}$ & 0 & 0 & 1 \\
\hline Other & 1 & 4 & \\
\hline
\end{tabular}

Table 2

Key word counts in literary trip descriptions: references to books/authors and sites.

\begin{tabular}{|l|c|}
\hline Key words and references in literary trip description & Numbers \\
\hline Book/books/series & 30 \\
\hline Writer/author & 2 \\
\hline Specific books named & 21 \\
\hline Specific writers named & 20 \\
\hline Writers mentioned in relation to their books/settings & 15 \\
\hline Writers mentioned in relation to birthplace/home/burial site & 5 \\
\hline
\end{tabular}


Table 3

Coding and thematic groupings of responses to Questions 6 and 7: 'describe a recent literary trip?' and 'differences between organised and independent trips?'

\begin{tabular}{|l|l|l|l|}
\hline Theme & $\begin{array}{l}\text { Theme 1: Co-creation } \\
\text { between visitor and text }\end{array}$ & $\begin{array}{l}\text { Theme 2: Role of the } \\
\text { imagination in the } \\
\text { literary trip } \\
\text { experience }\end{array}$ & $\begin{array}{l}\text { Theme 3: } \\
\text { Community of literary } \\
\text { knowledge }\end{array}$ \\
\hline Code & $\begin{array}{l}\text { Code 1 } \\
\text { Re-reading before trip }\end{array}$ & $\begin{array}{l}\text { Code 4 Emotional } \\
\text { response }\end{array}$ & $\begin{array}{l}\text { Code 7 } \\
\text { Like-minded } \\
\text { companionship }\end{array}$ \\
\hline & $\begin{array}{l}\text { Code 2 } \\
\text { Hunting/clues }\end{array}$ & $\begin{array}{l}\text { Code 5 } \\
\text { In-situ reference to } \\
\text { text }\end{array}$ & $\begin{array}{l}\text { Code 8 } \\
\text { expertise }\end{array}$ \\
\hline & $\begin{array}{l}\text { Code 3 } \\
\text { Creparation/research }\end{array}$ & Use of Imagination & \\
\hline
\end{tabular}

